\title{
TONG SAMPAH PINTAR DENGAN PERINTAH SUARA GUNA MENGHILANGKAN PERILAKU SISWA MEMBUANG SAMPAH SEMBARANGAN DI SEKOLAH
}

\author{
Deny Nusyirwan ${ }^{1)}$ \\ ${ }^{1}$ Fakultas Teknik, Program Studi Teknik Elektro, Universitas Maritim Raja Ali Haji (UMRAH) \\ ${ }^{1} J$ l. Politeknik Senggarang, Tanjungpinang 29100 \\ Email : 'denynusyirwan@umrah.ac.id
}

\begin{abstract}
Abstrak
Sampah pada masa ini sudah menjadi hal yang serius karena jumla sampah dari tahun ke tahun semakin meningkat seiring dengan bertambahnya jumlah penduduk. Tempat Pembuangan Akhir yang kelebihan kapasitas, ditambah dengan maraknya masyarakat yang membuang sampah sembarangan menyebabkan bencana alam dahsyat bagi umat manusia itu sendiri. Dari aspek kesehatan tentu membuang sampah sembarangan adalah perilaku yang merugikan banyak pihak, bau dari sampah menyebabkan polusi udara dan daerah menjadi tercemar. Oleh sebab itu, untuk meningkatkan kesadaran siswa di sekolah membuang sampah pada tempatnya dan sebagai solusi dari permasalahan membuang sampah sembarangan maka dirancang sebuah purwarupa tong sampah pintar dengan perintah suara berbasikan Arduino. Dengan menggunakan perintah suara, maka tong sampah akan mendekat selanjutnya otomatis membuka ketika tangan siswa mendekati tutup tong sampah. Penelitian dilaksanakan di SD 002 Tanjung Pinang Timur, dimulai dengan pendekatan sosial yang di integrasikan dengan design thinking untuk menghasilkan inovasi berbasis teknologi. Setelah mendapatkan solusi utama, dilanjutkan dengan purwarupa sederhana yang dipergunakan untuk uji fungsi dan manfaat bersama siswa calon pengguna teknologi. Dari hasil pengujian kepada siswa didapatkan bahwa purwarupa yang dihasilkan menarik dan mudah dipergunakan oleh para siswa nantinya serta sistem yang di uji coba juga sudah dapat berfungsi dengan baik
\end{abstract}

Kata Kunci : arduino, perintah, pintar, sampah, suara

Abstract
Garbage in this period has become a serious matter
because the amount of waste from year to year is
increasing along with the increase in population.
Excessive capacity final disposal sites, coupled with the
rise of people who dispose of littering cause massive
natural disasters for humanity itself. From the health
aspect of course littering is a behavior that harms many
parties, the smell from garbage causes air pollution and
the area becomes polluted. Therefore, to increase the
awareness of students in schools to dispose of garbage in

its place and as a solution to the problem of littering, a prototype of a smart garbage can was designed with an Arduino-based voice command. By using a voice command, the trash can will approach and then automatically open when the student's hand approaches the lid of the trash can. The study was conducted at SD 002 Tanjung Pinang Timur, starting with a social approach that was integrated with design thinking to produce technology-based innovations. After getting the main solution, followed by a simple prototype that is used to test the functions and benefits with prospective students of technology users. From the results of testing to students it was found that the resulting prototype was interesting and easy to use by students later and the system being tested also could function properly

Keywords: arduino, command, smart, garbage, voice

\section{Pendahuluan}

Sekolah merupakan lingkungan dimana para siswa melakukan kegiatan menimba ilmu pengetahuan dan aktifitas lain seperti aktivitas belajar, bermain, dan berolahrag. Aktivitas yang pada umumnya dimulai pada pagi dan berahir siang atau sore hari tentunya akan membutuhkan tenaga dan menguras pikiran. Oleh sebab itu, orang tua siswa membekali siswa dengan makanan dan minuman ataupun uang untuk belanja di kantin sekolah. Siswa yang makan dan minum di kantin sekolah, tidak perlu khawatir dengan sisa makanan, karena akan dibersihkan oleh petugas kantin, namun permasalahan timbul apabila makan dan minum dilakukan di luar daerah kantin karena tidak ada petugas yang akan membersihkan sisa makan siswa. Selain itu lokasi tong sampah yang juga berjauhan sehingga siswa secara sadar diri mendekati tong sampah dan membuang sisa makanan di tong sampah. Dari hasil pendekatan secara sosial di sekolah, dimana peneliti berintegrasi dengan berdiskusi bersama siswa di sekolah secara langsung, maka dapat ditemukan bahwa siswa yang makan dan minum setelah olahraga atau ketika istirahat untuk mengurangi rasa lapar dan juga haus, masih ada yang membuang sampah tidak pada tempat yang sudah disediakan..

Perilaku tidak membuang sampah pada tempatnya ini disebabkan karena letak tong sampah yang jauh dari 
lokasi siswa, dan khawatir tangan kotor ketika membuka tutup tong sampah sehingga siswa enggan untuk membuang sampah pada tempatnya sehingga sampah berserakan.

Dari permasalahan yang ditemukan tersebut, maka diusulkan sebuah inovasi berupa sebuah purwarupa berbasikan teknologi arduino uno, yaitu tong sampah pintar menggunakan perintah suara untuk menghilangkan perilaku siswa membuang sampah sembarangan di sekolah. Tong sampah akan bergerak menuju lokasi yang memberikan perintah dan tutup sampah akan membuka secara otomatis ketika tangan siswa mendekat. Dengan inovasi tersebut, siswa tidak perlu berjalan ke lokasi tong sampah dan tangan siswa juga tetap bersih terhindar dari kuman dan kotoran.

Penelitian ini dimulai dengan pengamatan secara langsung di sekolah, wawancara atau interview bersama siswa. Selanjutnya dilakukan tahapan brainstorming (diskusi secara bebas) untuk mendapatkan beberapa usulan solusi dari permasalahan yang ditemukan. Tahapan pembuatan purwarupa sederhana dengan bahanbahan yang ekonomis diperlukan untuk mendapatkan bentuk rancangan yang sesuai, dan tidak kalah pentingnya adalah tahapan pengujian purwarupa kepada siswa untuk mendapatkan masukan yang akan dipergunakan untuk evaluasi rancangan sebelumnya (apabila diperlukan). Keseluruhan tahapan ini disebut proses perancangan rekayasa dengan pendekatan double diamond.

\section{Kajian Pustaka}

Didalam penelitian ini, telah di lakukan kajian terhadap penelitian terdahulu yang akan di pergunakan sebagai batasan terhadap penelitian yang akan di lakukan, selain itu kajian pustaka juga akan menjelaskan mengenai purwarupa yang akan dirancang.

\subsection{Penelitian terdahulu}

Pada penelitian yang berjudul Perancangan dan pembuatan Smart Trash Bin berbasis Arduino Uno di Universitas Maarif Hasyim Latif adalah penelitian untuk menjaga air tetap pada tingkat kejernihan yang ditentukan sehingga layak untuk dikonsumsi dan dipergunakan untuk sanitasi. Sistem yang dirancang mempergunakan sensor kekeruhan yang akan mendetaksi tingkat kejernihan air, Sensor akan mengirimkan informasi kepada Arduino., apabila level kekeruhan berada pada batas yang ditentukan, maka arduino akan menggerakkan aktuator yang terintegrasi dengan pompa air sehingga proses penyaringan dimulai. [1]

Sedangkan pada penelitian dengan judul alat penyaring air kotor menjadi air bersih menggunakan mikrokontroller atmega 32 menjelaskan sebuah sistem penyaringan air bersih menggunakan mikrokontroller ATMega32 sebagai pengatur kerja pompa berdasarkan s tingkat kejernihan air. Sistem operasi yang dipergunakan adalah Windows 7 dengan bahasa pemograman Basic Bascom AVR dan Visual Basic 6.0. Hasil dari proses penyaringan akan ditampilkan di aplikasi pemograman dan juga pada LCD [2].

Penelitian dengan judul Alat Penyaringan Air Sederhana Dengan Metode Fisika menjelaskan mengenai pembuatan alat penyaringan air sederhana dengan menggunakan kerikil, ijuk dan arang sekam. Dari hasil uji coba didapatkan bahwa arang sekam sangat berperan didalam menjernihkan air, dimana semakin tebal makan air akan semakin jernih [3]

Pada penelitian yang berjudul .Perancangan Sistem Smart Trash Can menggunakan Arduino dengan Sensor Ultrasonik HC-SR04 adalah sebuah penelitian untuk mendorong orang tertarik untuk membuang sampah pada tmpatnya. Tong sampah yang kotor telah membuat orang enggan untuk membuka tong sampah, pada ahirnya sampah akan di buang tidak pada tempatnya dan berserakan sehingga akan dapat mengajdi sumber dari berbagai penyakit secara langsung atau pun yang terbawa oleh udara. Penelitian ini akan menghasilkan sebuah purwarupa dengan menggunakan sensor ultrasonik untuk mendeteksi orang yang mendekat,dan apabila sudah mencapai jarak yang ditentukan maka tutup sampah akan terbuka dengan otomatis. Semua masukan dan luaran akan diatur oleh mikrokontroler. [4]

\subsection{Landasan Teori}

Purwarupa Tong Sampah Pintar dengan Perintah Suara terdiri dari 2(dua) bagian utama. Yang pertama adalah fungsi penggerak untuk membawa tong sampah setelah mendapatkan perintah suara yang terhubung secara nirkabel melalui bluetooth yang terdapat pada telepon pintar dan modul bluetooth pada arduino. Pada bagian kedua adalah fungsi otomatis dengan memanfaatkan sensor ultrasonik maka tutup sampah dapat membuka ketika tangan siswa sudah mendekat dan menutup ketika sudah menjauh. Dan LCD akan menampilkan pesan text yang sudah di programkan..Sila lihat Gambar 1.

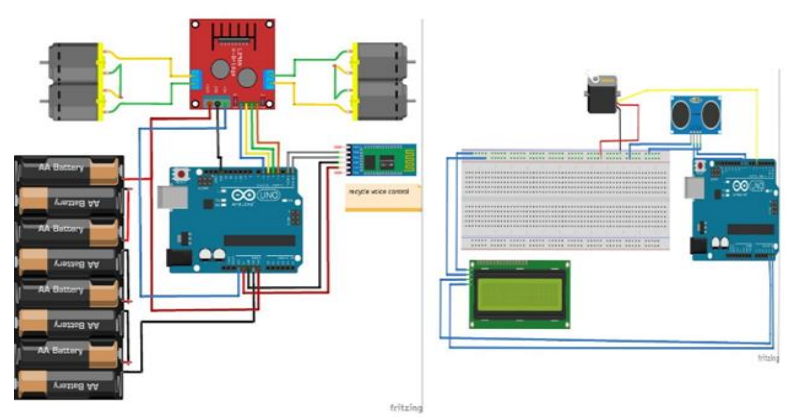

Gambar 1. Rangkaian Elektronika Sistem Tong Sampah Pintar Dengan Perintah Suara

\subsection{Komponen purwarupa}

Adapun komponen yang diperlukan untuk pembuatan purwarupa dengan estimasi harga adalah sila lihat pada Tabel 1.

Tabel 1. Estimasi anggaran ( Bukalapak, diakses 17 Juli 2019) 


\begin{tabular}{|c|c|c|c|c|}
\hline No. & Barang & Jumlah & $\begin{array}{c}\text { Harga } \\
\text { Satuan (Rp) }\end{array}$ & $\begin{array}{c}\text { Harga } \\
\text { Total (Rp) }\end{array}$ \\
\hline 1 & $\begin{array}{l}\text { Arduino } \\
\text { Uno R3 }\end{array}$ & 2 & 48000 & 96000 \\
\hline 2 & Breadboard & 2 & 35000 & 70000 \\
\hline 3 & $\begin{array}{l}\text { Kabel } \\
\text { jumper }\end{array}$ & 30 & 1000 & 30000 \\
\hline 4 & Resistor & 4 & 500 & 2000 \\
\hline 5 & Bluetooth & 1 & 59500 & 59500 \\
\hline 6 & LCD & 1 & 25000 & 25000 \\
\hline 7 & $\mathrm{I} 2 \mathrm{C}$ & 1 & 11000 & 11000 \\
\hline 8 & $\begin{array}{l}\text { Mikro } \\
\text { servo }\end{array}$ & 1 & 40000 & 40000 \\
\hline 9 & $\begin{array}{l}\text { Kerangka } \\
\text { kendaraan }\end{array}$ & 1 & 150000 & 150000 \\
\hline \multirow[t]{2}{*}{10} & $\begin{array}{l}\text { Sensor } \\
\text { Ultrasonik }\end{array}$ & 1 & 22000 & 22000 \\
\hline & Jumlah & & & 505500 \\
\hline
\end{tabular}

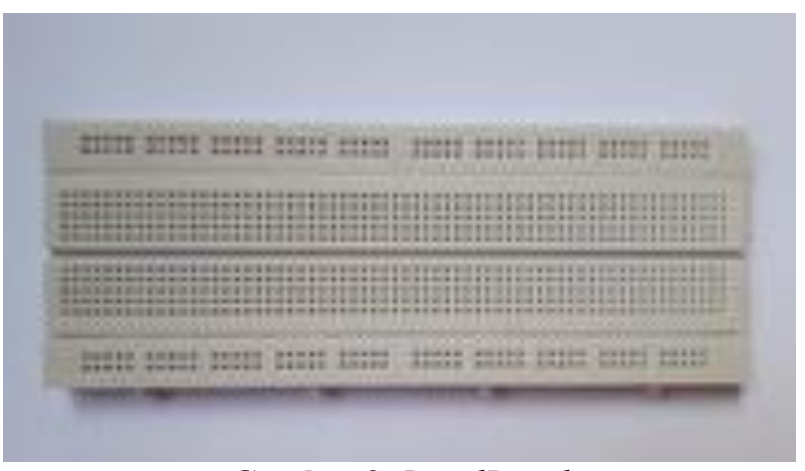

Gambar 3. BreadBoard

\subsubsection{Kabel jumper}

Kabel jumper adalah kabel yang di pergunakan untuk menghubungkan satu komponen dengan komponen lain ataupun menghubungkan jalur rangkaian yang terputus pada breadboard, sila lihat Gambar 4.

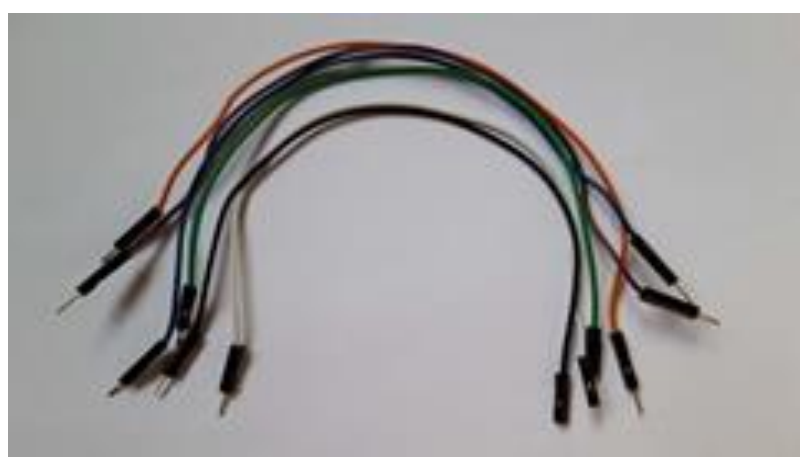

Gambar 4. Kabel Jumper

\subsubsection{Modul Bluetooth}

Modul Bluetooth adalah sebuah alat yang dipergunakan untuk menghubungkan sebuah perangkat dengan perangkat lainnya tanpa kabel. Sila lihat Gambar 5.

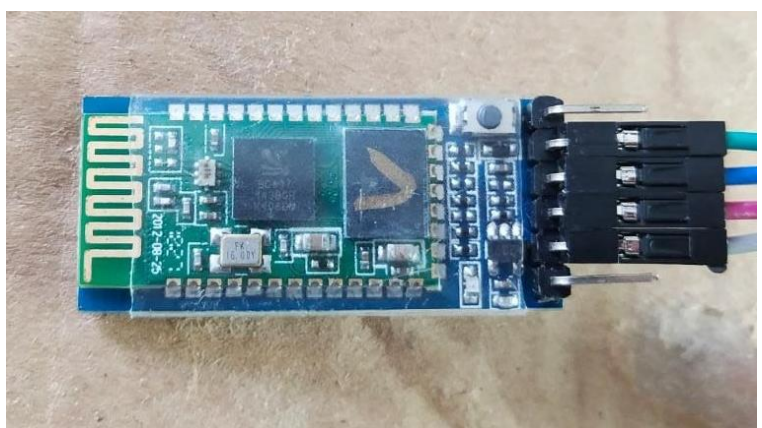

Gambar 5. Modul Blueetooth

\subsubsection{Resistor}

Resistor adalah komponen elektronika pasif yang memiliki nilai resistansi atau hambatan tertentu yang berfungsi untuk membatasi dan mengatur arus listrik dalam suatu rangkaian elektronika. Fungsi Resistor di dalam rangkaian elektronika memiliki pembatas dan pengatur arus listrik, serta pembagi dan penurun tegangan listrik. Sila lihat Gambar 6. 


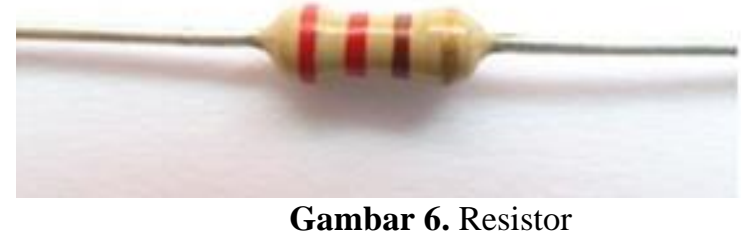

Gambar 6. Resistor

\subsubsection{Liquid Cristal Display}

Liquid Cristal Display (LCD) adalah sebuah komponen elektronika yang dipergunakan untuk menampilkan tulisan, karakter dan huruf, LCD menggunakan kristal cair sebagai penampil utama. Dalam modul LCD terdapat mikrokontroller yang berfungsi sebagai pengendali tampilan karakter dilengkapi dengan memori dan register.Juga terdapat pin, yang salah satunya berfungsi untuk jalur untuk memberikan data karakter yang ingin ditampilkan Sila lihat Gambar 7.

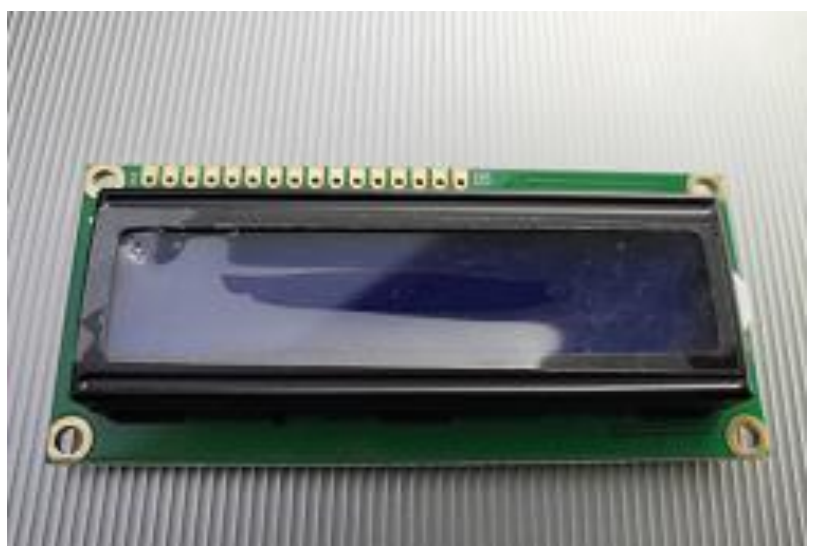

Gambar 7. Liquid Cristal Display (LCD)

\subsubsection{Modul I2C (Inter Integratred Circuit)}

Penggunakan I2C Serial pada LCD dapat menghemat jumlah pin yang tersedia di dalam arduino dan membuat sketch pemrograman menjadi simple serta dapat menjaga LCD agar tidak cepat rusak. Sila lihat Gambar 8.

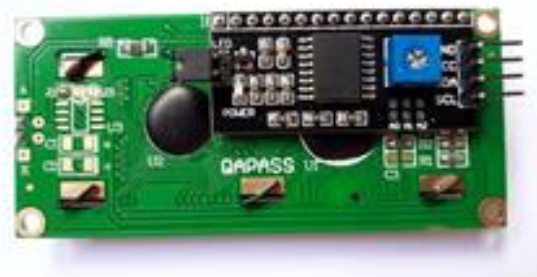

Gambar 8. I2C

\subsubsection{Mikro Servo}

Mikro Servo adalah sebuah motor DC yang dilengkapi dengan rangkaian kendali. Motor servo disusun dari sebuah motor DC, roda gigi, potensiometer dan rangkaian kontrol. Potensiometer memiliki berfungsi untuk menentukan batas maksimum putaran sumbu motor. Sila lihat Gambar 9.

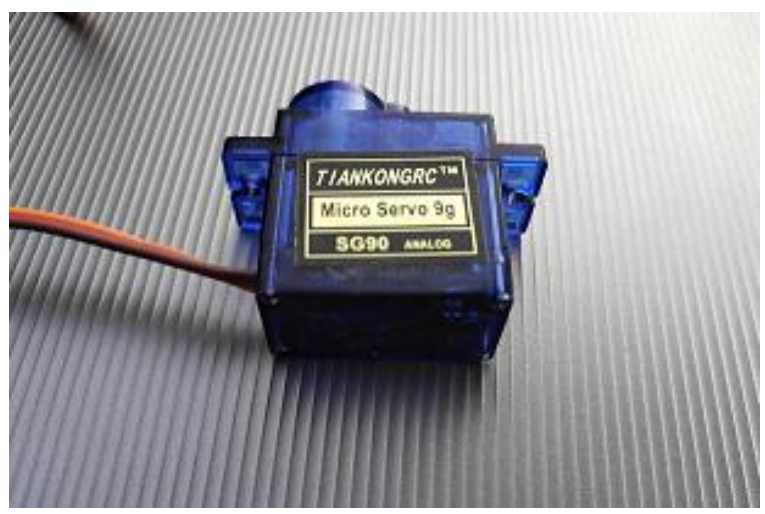

Gambar 9. Mikro Servo

\subsubsection{Kerangka kendaraan}

Kerangka kendaraan adalah lokasi untuk menempatkan Arduino dan komponen yang akan menggerakkan kendaraaan. Sila lihat Gambar 10.

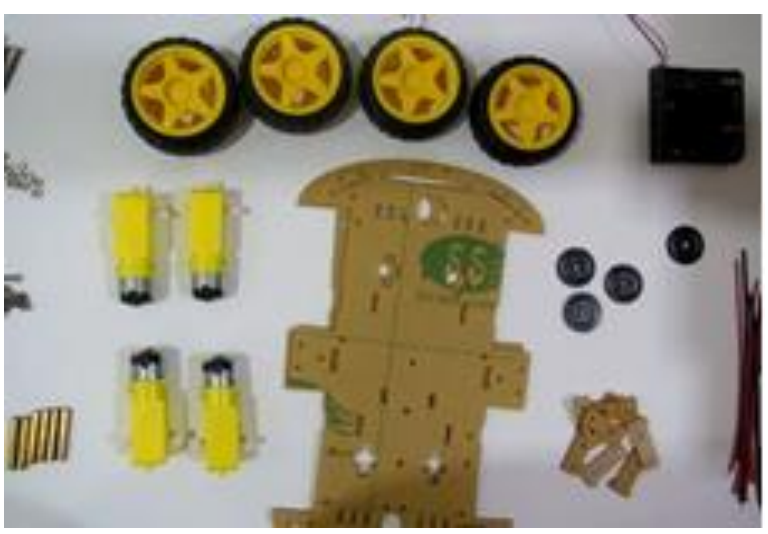

Gambar 10. Kerangka kendaraan

\subsubsection{Sensor ultrasonik}

Sensor ultrasonik berfungsi untuk mengubah besaran bunyi menjadi besaran listrk dan sebaliknya. Sensor ini mampu mendeteksi jarak dari suatu obyek dengan cara memancarkan gelombang ultrasonik dengan frekuensi $40 \mathrm{KHz}$ dan kemudian mendeteksi pantulannya. Sensor ini dapat mengukur jarak antara 3 cm sampai $300 \mathrm{~cm}$. Sila lihat Gambar 11.

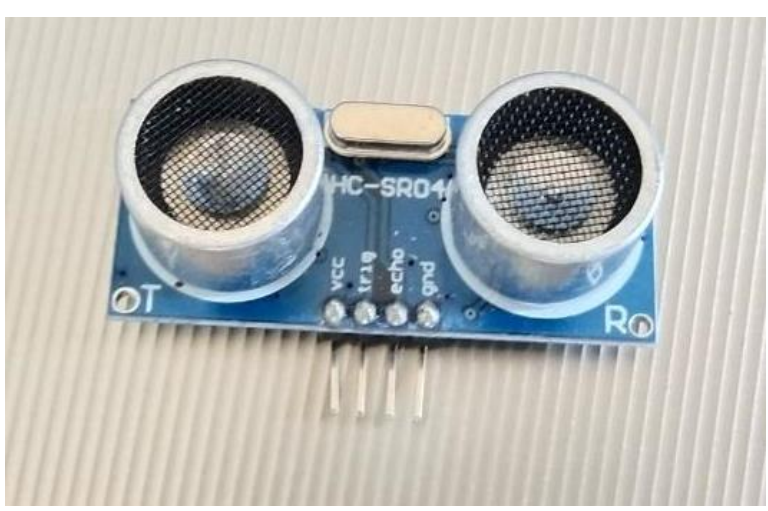

Gambar 11. Sensor Ultrasonik 


\section{Metode}

Peranan penting bagi ilmuwan pada abad ke-21 adalah berperan serta dalam mendidik masyarakat tentang metode dan hasil proses ilmiah [5], oleh sebab itu diperlukan proses desain rekayasa untuk mampu menghasilkan inovasi berbasiskan teknologi yang semakin berkembang dan memiliki fungsi yang tepat dan mudah untuk digunakan. Jika di masa lalu desainer dievaluasi hanya berdasarkan pada keterampilan teknis mereka, di masa depan akan lebih banyak lagi kebutuhan untuk desainer yang bersedia bekerja dengan pendekatan yang lebih sistemik dan strategis dalam skala yang lebih besar [6]. Proses Desain Rekayasa adalah merupakan sebuah proses didalam mendesain dengan berpusat kepada pengguna. dimulai dengan etnografi hingga menghasilkan sebuah purwarupa yang merupakan sebuah konsep solusi yang sesuai dengan kebutuhan di masyarakat.

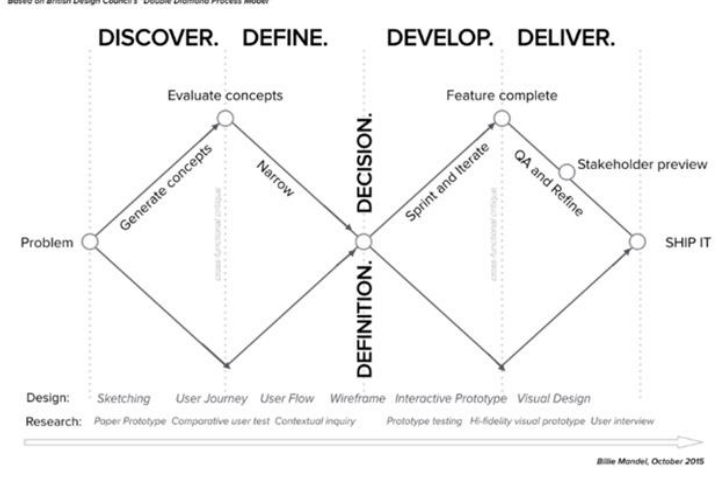

Gambar 12. Tahapan pada Proses Desain Rekayasa [7]

Proses ini memiliki 4 tahapan, pada tahapan awal dimulai dengan observasi secara luas di masyarakat untuk mendapatkan permasalahan-permasalahan, tahapan kedua adalah proses pengerucutan dengan melakukan pemilihan permasalahan utama, tahapan ketiga adalah mengembangkan ide-ide sebagai solusi terhadap permasalahan utama dan tahapan terahir adalah menetukan solusi utama untuk dapat dilanjutkan ke tahapan pembuatan purwarupa dan pengujian terhadap pengguna, sila lihat Gambar 12. Dalam tahapan pengujian terhadap pengguna akan terdapat proses iterasi untuk mendapatkan masukan untuk evaluasi inovasi nantinya.

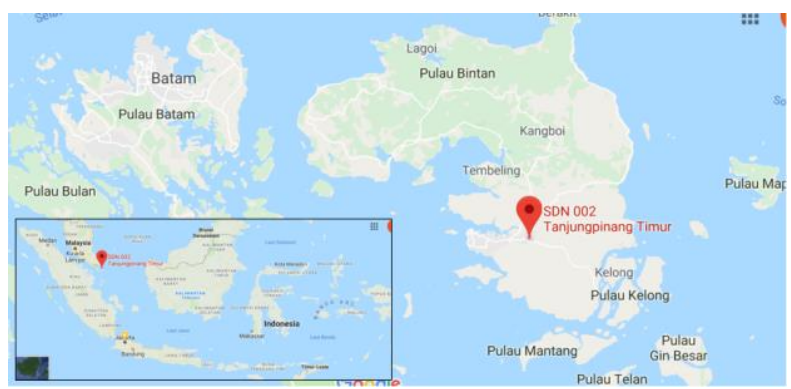

Gambar 13. Lokasi SDN 002 Tanjung pinang timur [8

Desain dan pemasaran adalah dua bagian penting dalam proses penelitian untuk melakukan pengembangan produk dan menghasilkan inovasi berbasis teknologi. Kedua bidang tersebut dapat saling melengkapi namun memiliki fokus yang berbeda. Peneliti untuk bidang desain sangat ingin tahu apa yang benar-benar dibutuhkan oleh calon pengguna dan bagaimana sebenarnya pengguna akan menggunakan produk yang sedang dipersiapkan. Sedangkan untuk peneliti di bidang pemasaran ingin tahu apa yang akan dibeli pengguna, termasuk mempelajari bagaimana pengguna membuat keputusan pembelian. Oleh sebab itu, dengan tujuan yang berbeda ini akan mengarahkan kedua kelompok tersebut untuk mengembangkan metode penyelidikan yang berbeda pula. Desainer cenderung menggunakan metode observasi kualitatif yang dengannya mereka dapat mempelajari orang secara mendalam, memahami bagaimana mereka melakukan kegiatan mereka dan faktor lingkungan yang ikut berperan [8]. Metode ini sangat memakan waktu, sehingga didalam penelitian ini hanya memeriksa sejumlah kecil orang.. Adapun metode observasi yang dipergunakan adalah metode observasi peneliti sebagai peserta (observer as participant), yaitu kelompok yang sedang diteliti mengetahui tentang keberadaan peneliti, namun peneliti tidak ikut serta melakukan kegiatan dan aktifitas didalam kelompok yang sedang diteliti. Lokasi penelitian dilakukan di SDN002 Tanjung pinang timur, Kepulauan Riau, lihat Gambar 13.

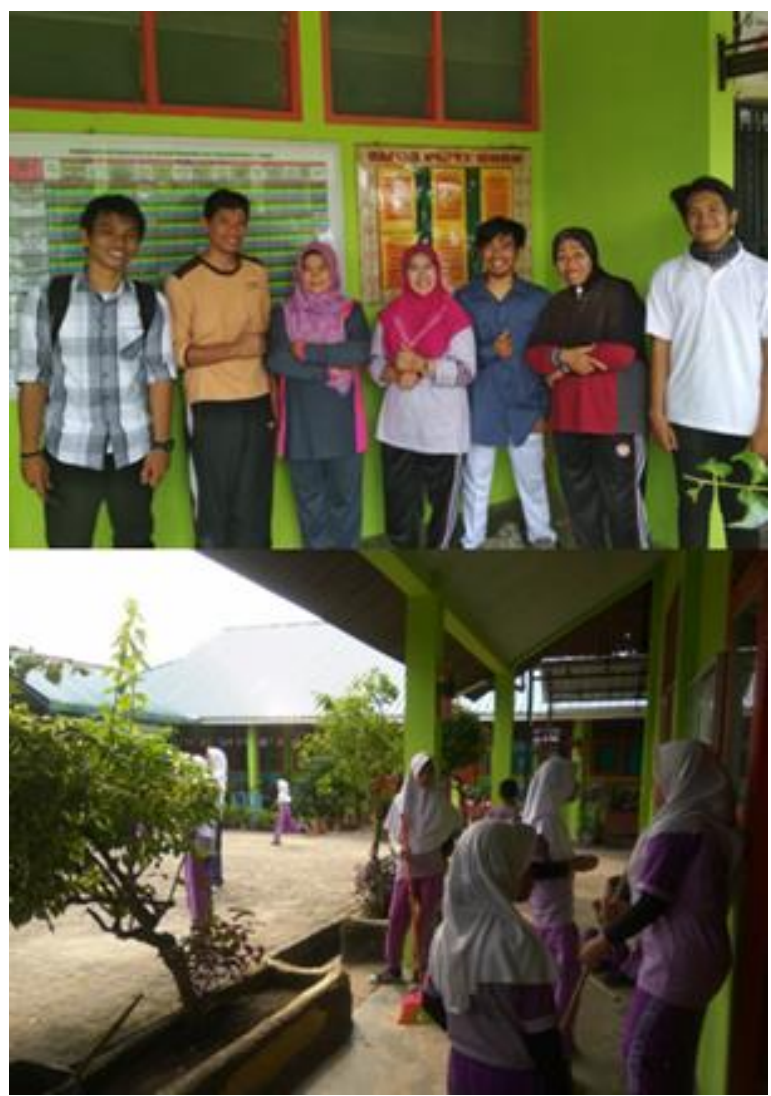

Gambar 14. Suasana di SDN 002 Tanjung pinang 
timur

Langkah awal dari Proses Desain Rekayasa, yang merupakan aktivitas pegamatan atau observasi secara langsung ke masyarakat di suatu daerah untuk mendapatkan data yang akurat sehingga mampu menghasilkan sebuah solusi yang tepat. Pada Gambar 14 menampilkan keadaaan di SDN 002 Tanjung pinang timur untuk mendapatkan data-data yang di perlukan.

Metode etnografi yang diterapkan pada penelitian ini adalah peneliti sebagai peserta, dimana kelompok yang sedang diteliti mengetahui tentang keberadaan peneliti, namun peneliti tidak ikut serta melakukan kegiatan dan aktifitas didalam kelompok yang sedang diteliti [9]. Pada Gambar 15 memperlihatkan peneliti melakukan proses pengumpulan informasi di SDN 002 Tanjung pinang timur.

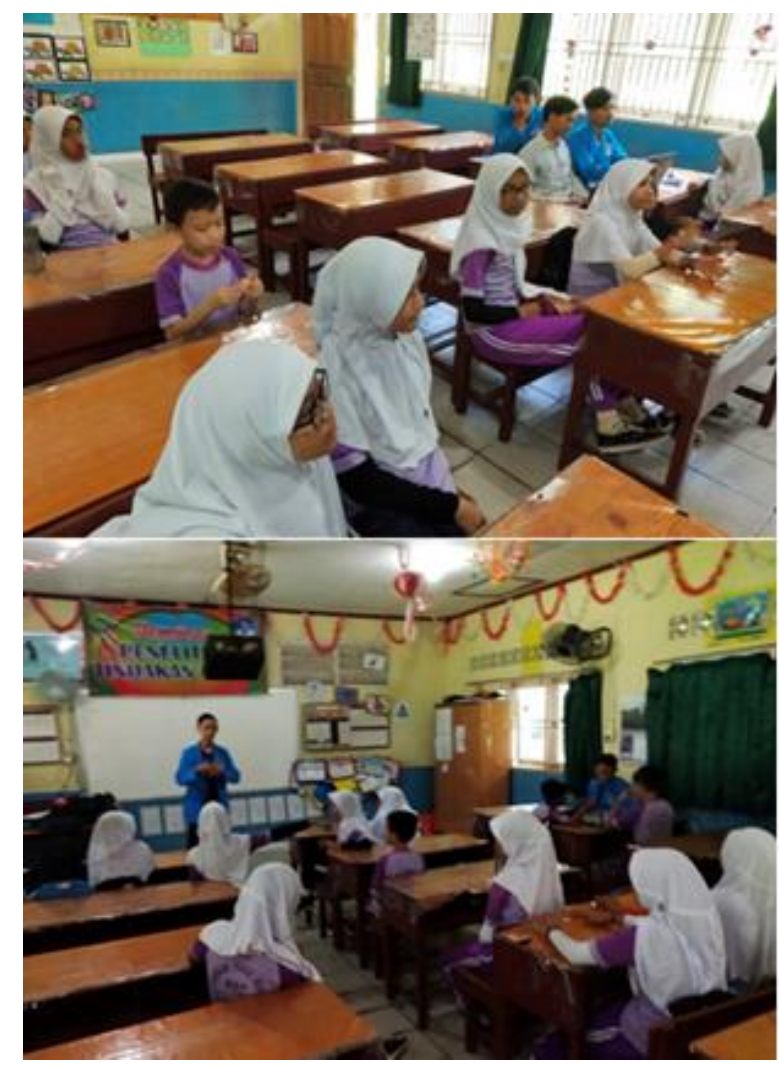

Gambar 15. Mengumpulkan informasi mengenai permasalahan yang terdapat di sekolah melalui siswa

\section{Hasil dan Pembahasan}

Tahapan selanjutnya adalah curahan gagasan permasalahan yang ditemukan di sekolah dari hasil observasi, dimana semua permasalahan yang ditemukan akan di dokumentasikan. Proses ini adalah merupakan tahapan yang penting, karena sangat diharapkan bahwa solusi yang akan dihasilkan adalah merupakan solusi yang dibutuhkan, bukan solusi yang diminta oleh calon pengguna. Pola penyampaian gagasan secara bebas akan sangat diperlukan untuk memotivasi peneliti untuk mampu berpikir inovatif dan kreatif. Curahan gagasan yang bersifat luas adalah merupakan pondasi bagi rekayasawan untuk mampu menghasilkan sebuah inovasi yang berbasiskan teknologi. Hal ini sering dipahami dengan $\mathrm{T}$ concept, dimaksudkan bahwa inovasi yang dihasilkan memiliki pengaruh yang luas dan mendalam. Pada Gambar 16 dapat dilihat proses pengumpulan masalah-masalah yang sangat berkaitan dengan kejadian di sekolah selama melakukan observasi dan wawancara

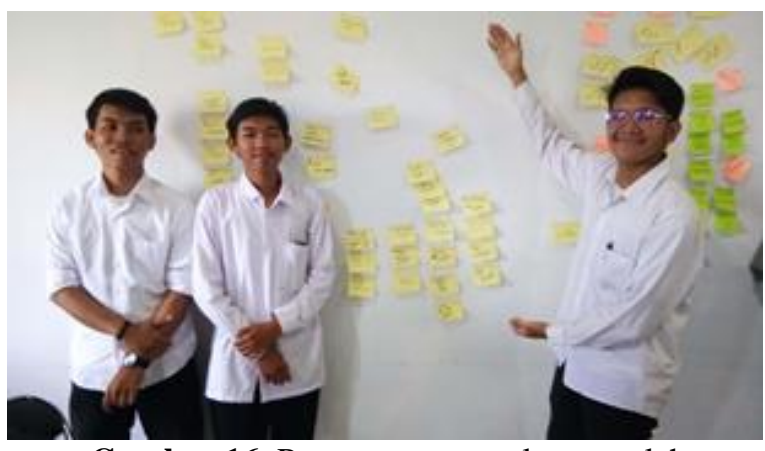

Gambar 16. Proses pengumpulan masalah

Permasalahan utama adalah satu permasalahan yang akan dijadikan landasan untuk langkah penentuan solusi, dalam tahapan ini akan dilakukan proses pengerucutan masalah, dimulai dengan pengelompokan masalah dan selanjutnya di pilih satu masalah saja.

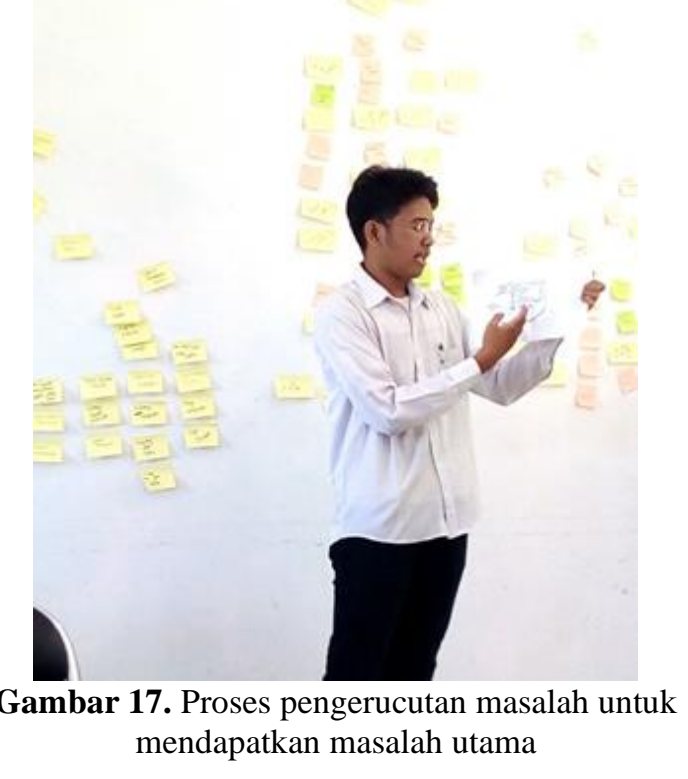

Proses diskusi bersama sesama anggota kelompok dengan saling memberikan penjelasan terhadap masalah yang akan dijadikan masalah utama diperlukan untuk mendapatkan informasi-informasi yang belum dapat disampaikan pada tahapan sebelumnya. Adapun permasalahan utama dari penelitian ini adalah sampah berserakan di lingkungan sekolah akibat siswa tidak membuang sampah pada tempatnya. Tahapan curahan gagasan solusi dari masalah utama dilakukan setelah mendapatkan permasalahan utama. Dalam tahapan ini dipresentasikan konsep solusi bersama anggota peneliti lainnya. lihat Gambar 17. 


\subsection{Purwarupa}

Tahapan yang sudah mulai memerlukan pembiayaan adalah tahapan pembuatan purwarupa. Oleh sebab itu pada Proses Desain Rekayasa ini, menekankan untuk mampu menghasilkan purwarupa sederhana yang ekonomis dan fleksible, dengan maksud bahwa perubahan rancangan dapat dilakukan dengan mudah dan tidak akan memerlukan pembiayaan yang besar. Purwarupa dalam tahapan ini lebih dikenal dengan istilah low resolution prototype [10]. Dapat dilihat pada Gambar 18 adalah rangkaian komponen dari Tong Sampah otomatis membuka dan menutup dan purwarupa sederhan dan ekonomis yang sudah di integrasikan dengan cardboard .

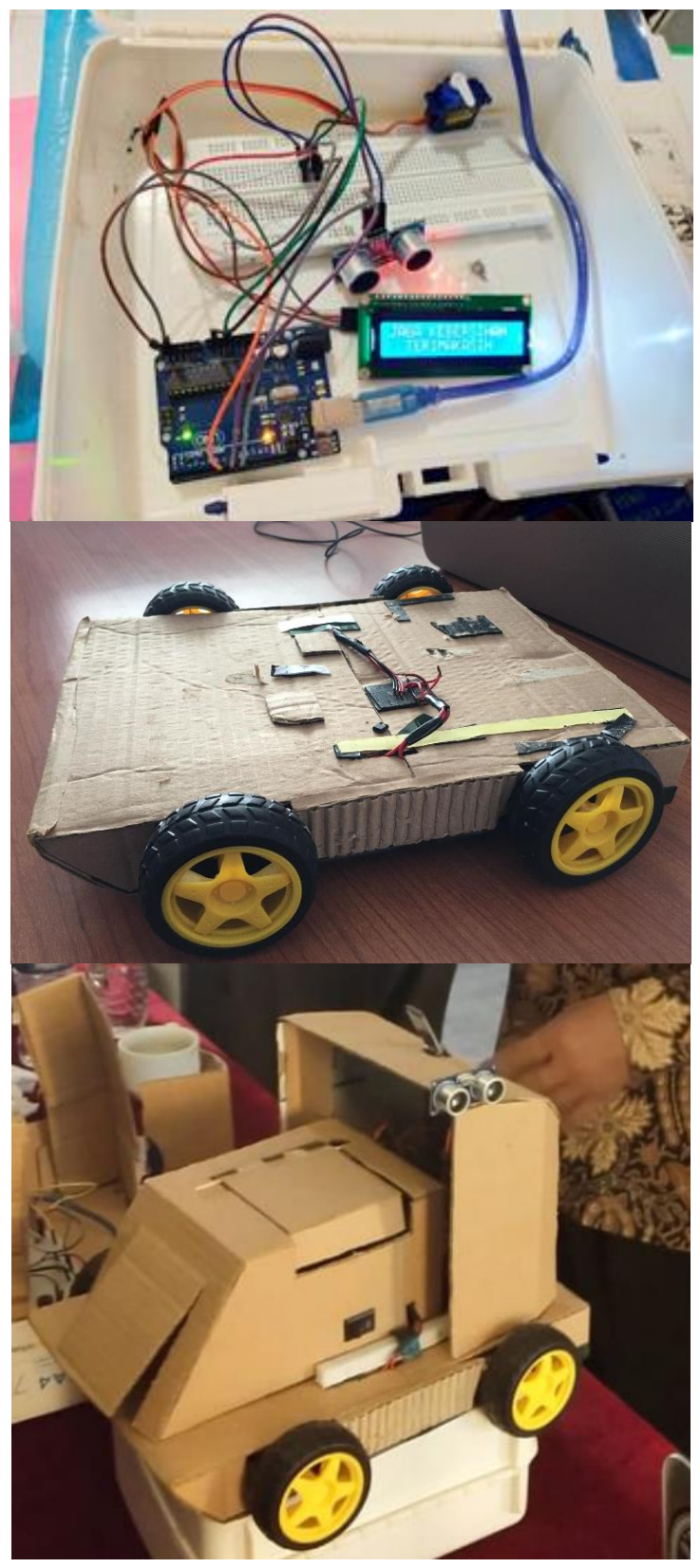

Gambar 18. Purwarupa Sederhana Tong Sampah Pintar Dengan Perintah Suara

\subsection{Pengujian Kegunaan}

Pengujian kegunaan adalah proses evaluasi terhadap inovasi yang dirancang dengan berbasis pengguna. Pada tahapan ini pengguna akan berpartisipasi dan berinteraksi secara langsung dengan purwarupa sederhana yang dihasilkan dari proses sebelumnya. Pengguna akan diminta untuk melakukan tugas tertentu atau hanya menjelajahinya secara bebas, sementara perilaku pengguna diamati dan dicatat untuk mengidentifikasi kelemahan desain yang menyebabkan kesalahan atau kesulitan pengguna. Selama pengamatan ini, Setelah kelemahan desain telah diidentifikasi, rekomendasi desain diusulkan untuk meningkatkan kualitas ergonomis produk [11]

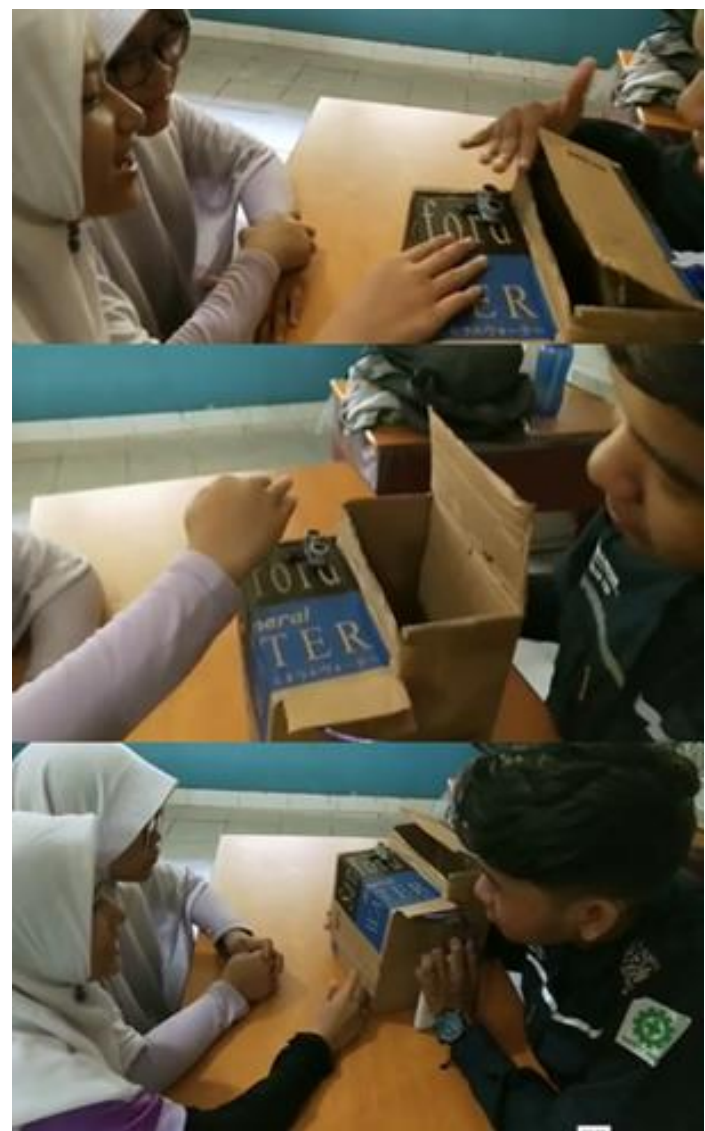

Gambar 19. Pengujian kegunaan bersama siswa sekolah dasar

Pengalaman pengguna akan memperluas pandangan tentang interaksi produk dengan pengguna dari aspek emosional. Adapun motivasi dari proses pengalaman pengguna adalah untuk mengembangkan pengalaman dan emosi positif. Oleh karena itu, produk harus memenuhi kebutuhan psikologis dan motif pelanggan [12]. Pada Gambar 19 menampilkan pengujian kegunaan bersama siswa sekolah dasar, dimana tutup sampah akan membuka ketika tangan siswa mendekat dan menutup kembali ketika menjauh. 
Setelah mengatur library di dalam sketch program, selanjutnya mengatur input dan output. Pada purwarupa ini memiliki 4 output yaitu 4 motor DC yang masingmasing nya tegangannya $3 \mathrm{~V}-\mathrm{DC}$ yang berfungsi sebagai penggerak roda depan dan roda belakang yang bisa di control melalui APK Bluetooth pada telepon pintar melalui perintah suara. Sila lihat Gambar 22.

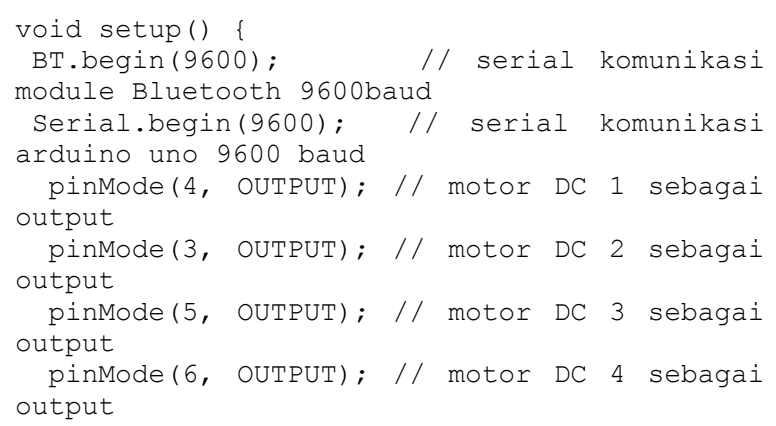

Gambar 22. void setup mengatur input dan output

Di dalam void loop diatur fungsi perulangan dari masing-masing kondisi, karena motor DC yang ada di dalam prototype bergerak berdasarkan perintah suara yang diterima langsung dari module Bluetooth dan fungsi suara tersebut diucapkan lewat voice google. Maka perulang yang digunakan pada prototype ini adalah if/else jika/maka. If module Bluetooth menerima perintah maju maka motor DC akan bekerja untuk memutar motor DC1 dan 3, else if/maka jika kita Bluetooth menerima perintah suara mundur motor DC2 dan 4 akan bekerja untuk memutar motor dan bergerak mundur, else if/makan jika Bluetooth menerima perintah suara kanan motor DC1 dan 3 akan bekerja untuk memutar motor, else if/ maka jika Bluetooth menerima perintah suara kiri motor DC1 dan 4 akan bekerja memutar motor. Sila lihat Gambar 23.

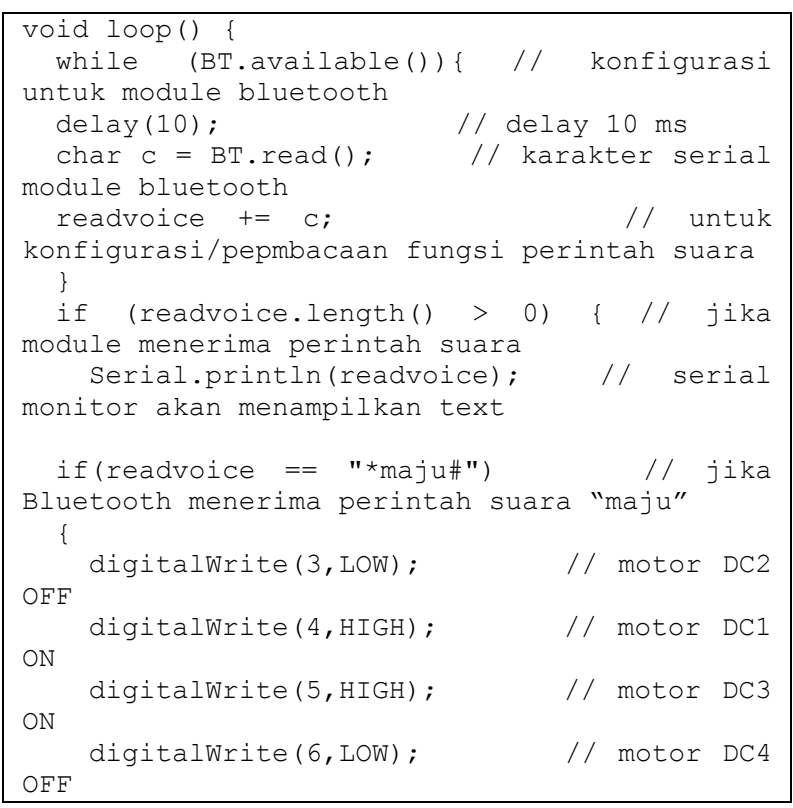

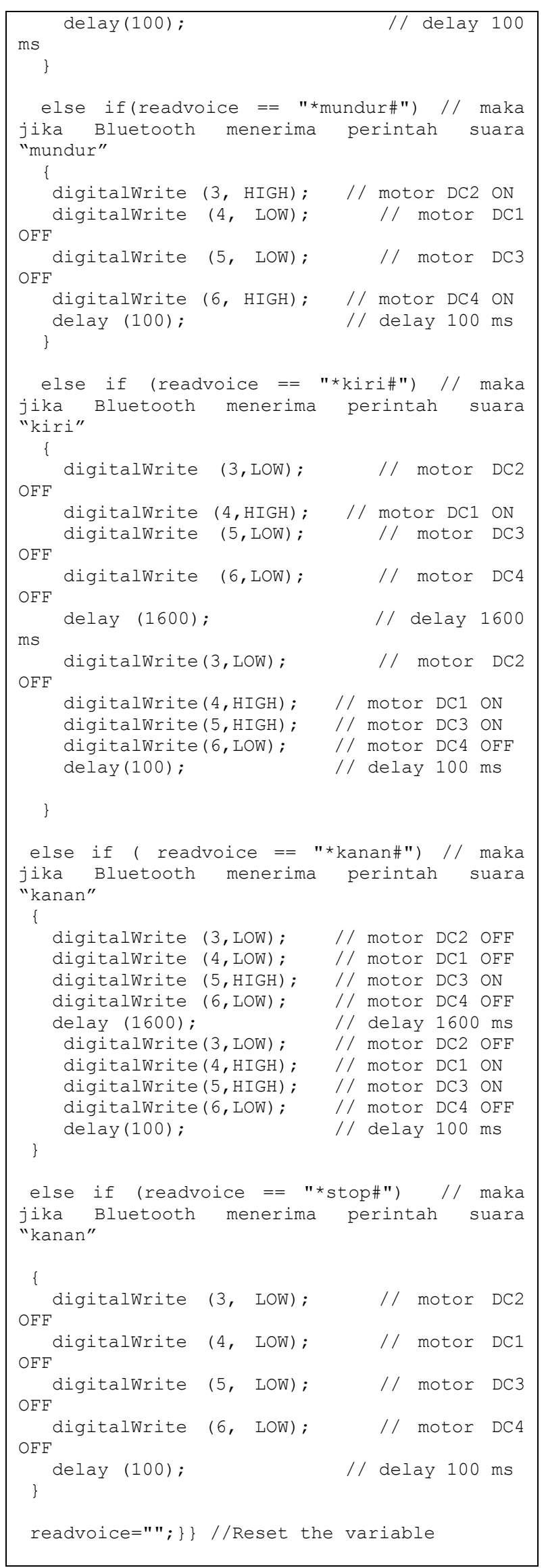

Gambar 23. void loop fungsi perulangan 
Selanjutnya adalah skematik diagram dengan fungsi otomatis yang menggunakan sensor ultrasonic, tutup sampah dapat membuka ketika tangan siswa sudah mendekat dan menutup ketika sudah menjauh dapat dilihat pada Gambat 24.

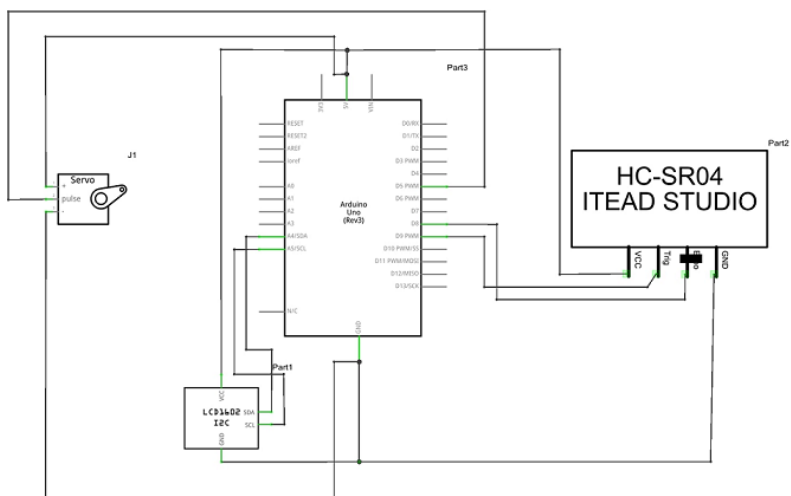

Gambar 24. Skematik diagram dari fugsi buka dan tutup otomatis pada tong sampah

Purwarupa menggunakan komponen servo, LCD I2C, dan sensor ultrasonic, maka dimasukan library nya terlebih dahulu agar program membaca komponen tersebut. Untuk pin trigpin pada ultrasonic di letakan di pin 9 arduino dan echo pin di letakan di pin 8 arduino. Sila lihat Gambar 25

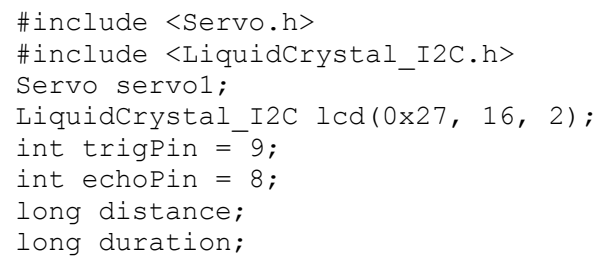

\section{Gambar 25. Inisialisasi dan memasukan library} komponen.

Jika menggunakan serial interface I2C pada LCD $16 \times 2$ maka harus mengetahui terlebih dahulu alamat I2C tersebut, jika alamat I2C yang di masukan dalam program salah maka $\mathrm{I} 2 \mathrm{C}$ tidak akan dapat berfungsi dan membuat LCD $16 \times 2$ eror. Pemakaian I2C sangat disarankan jika menggunakan LCD 16x2 agar LCD tersebut lebih aman dan terhindar dari masalah-masalah yang tidak diinginkan. Sila lihat Gambar 26

LiquidCrystal_I2C $1 \mathrm{Cd}(0 \times 27,16,2)$;

\section{Gambar 26. Alamat I2C serial interface.}

Di dalam void setup ditentukan fungsi dari komponen yang digunakan, apakah menjadi input atau output. Pada purwarupa ini trigpin sebagai output dan echopin sebagai input. dan didalam void setup LCD 16x2 di perintahkan untuk menampilkan text monitor "JAGA
KEBERSIHAN" dan "TERIMAKASIH” dengan posisi cursor 0,1. Sila lihat Gambar 27

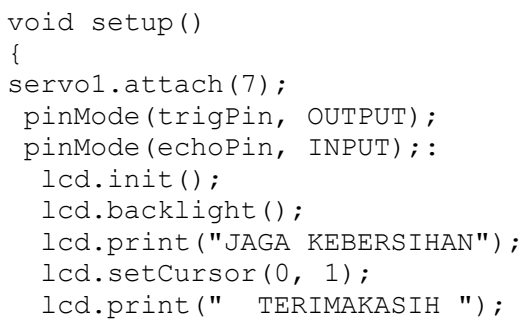

Gambar 27. Void setup untuk mengatur input/output komponen.

Void loop adalah fungsi perulangan, fungsi perulangan pada purwarupa ini diatur untuk radius putar servo agar saat servo berputar dari 0 derajat ke 90 derajat dan kembali lagi ke 0 derajat, pada saat diletakan tangan didepan sensor ultrasonik maka servo akan berputar dari 0 derajat ke 90 derajat dan LCD 16x2 akan menampilkan text monitor "JAGA KEBERSIHAN" dan " TERIMAKASIH". Dan begitulah seterusnya kerja dari program tersebut. Sila lihat Gambar 28

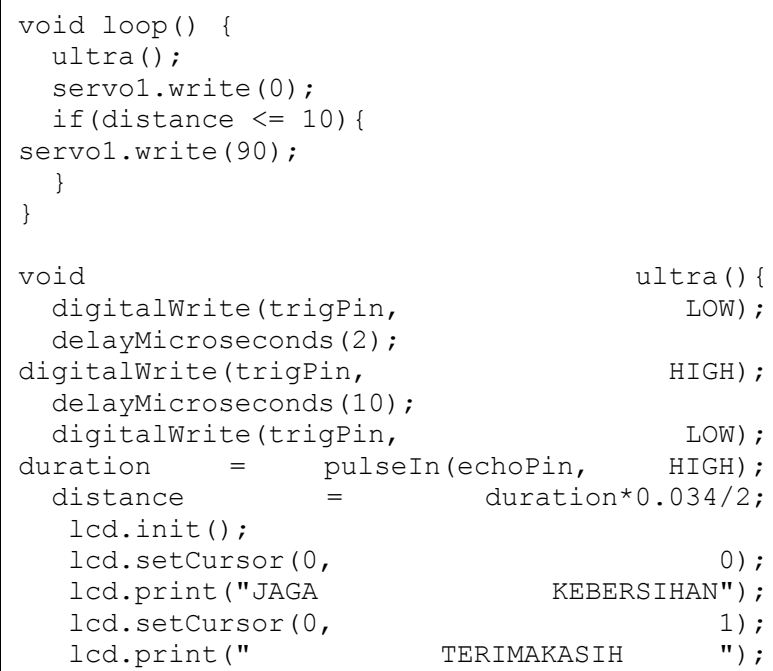

Gambar 28. Fungsi perulangan / void loop

\section{Kesimpulan}

Sampah merupakan permasalahan yang perlu diatasi bersama, salah satu usaha adalah dengan memulai kebiasaan untuk membuang sampah pada tempatnya. Penelitian ini menitik beratkan pada upaya untuk menumbuhkan kebiasaan siswa sadar kebersihan dengan membuang sampah pada tempatnya dan menghilangkan perilaku siswa membuang sampah sembarangan di 
lingkungan sekolah dengan cara memanfaatkan inovasi berbasis teknologi yaitu Tong sampah pintar dengan perintah suara. Inovasi yang memanfaatkan teknologi mikrokontroler arduino uno terdiri dari dua bagian, yaitu bagian penggerak untuk membawa tong sampah setelah mendapatkan perintah suara yang terhubung secara nirkabel melalui bluetooth dan bagian otomatis dengan memanfaatkan sensor ultrasonik maka tutup sampah dapat membuka ketika tangan siswa sudah mendekat dan menutup ketika sudah menjauh.

Dari hasil pengujian purwarupa bersama siswa calon pengguna inovasi, telah didapatkan bahwa inovasi yang dihasilkan menarik dan mudah dipergunakan oleh para siswa nantinya serta sistem yang di uji coba juga sudah dapat berfungsi dengan baik. Pada ahir proses pengujian siswa berharap sistem nirkabel yang terdapat pada purwarupa dapat menjangkau jarak yang lebih jauh.

Berdasarkan hasil pengujian bersama calon pengguna yang memuaskan tersebut, maka dapat disimpulkan juga bahwa proses perancangan rekayasa untuk menghasilkan sebuah inovasi, memerlukan sebuah proses awal pendekatan secara sosial dengan cara interaksi langsung bersama calon pengguna inovasi, yang di integrasikan dengan pola pikir secara luas sangat diperlukan untuk dapat menemukan permasalahan utama yang selanjutnya menjadi tujuan untuk dapat menghasilkan inovasi berbasis teknologi yang bermanfaat bagi calon pengguna tersebut.

\section{Ucapan Terima Kasih}

Terima kasih kepada sekolah SDN 002 Tanjung Pinang Timur yang bekerjasama dengan jurusan teknik elektro dalam usaha untuk menghasilkan inovasi berbasiskan teknologi di sekolah dan redaksi Jurnal Teknoinfo Universitas Teknokrat Indonesia yang telah memberikan kesempatan untuk publikasi.

\section{Daftar Pustaka}

[1] Sukarjadi, D. T. Setiawan, Arifiyanto, \& M. Hatta, "Perancangan dan pembuatan Smart Trash Bin berbasis Arduino Uno di Universitas Maarif Hasyim Latif', Jurnal Teknika Universitas Maarif Hasyim Latif, Vol. 1, No. 2, pp. 101-110, 2017.

[2] P. E. Nurcahyono, Tempat Sampah Pintar menggunakan Mikrokontroler ATMega 8535, Proyek Ahir D3, Universitas Negeri Yogyakarta,2012

[3] M. A. M. Nabil, "Kotak Sampah Pintar menggunakan Sensor Ultrasonik berbasis Mikrokontroler Arduino Uno", Tugas Ahir S1, Universitas Islam Indonesia, 2018

[4] D. Ubaidillah "Perancangan Sistem Smart Trash Can menggunakan Arduino dengan Sensor Ultrasonik HC-SR04", Tugas Ahir S1, Sekolah
Tinggi Manajemen Informatika dan Komputer AMIKOM Yogyakarta, 2015

[5] S. Kastner, \& R. T. Knight, "Bringing Kids into the Scientific Review Process". Neuron, Vol. 93, Edisi 1, pp. 12-14, 2017

[6] A. Irbīte, \& A. Strode, Design thinking models in design research and education, Proceedings of the International Scientific Conference. Vol. IV, pp. 488-500, 2016

[7] Design Strategy Case Study: FiveStars, http://www.billiemandel.com/fivestars-designstrategy, retrieved July 19, 2010.

[8] https://www.google.com/maps/place/Jl.+Tj.+Siamb ang/@0.87153,104.4258334,10z/data $=! 4 \mathrm{~m} 5$ !3m4!1 s0x31d90d330974d24d:0xcd400be497706ac!8m2!3 d0.87153!4d104.4280221, retrieved July 19, 2019.

[9] C. Wagner, B. Kawulich, \& M. Garner, Collecting Data Through Observation, Doing Social Research: A global context, McGraw Hill, 2012

[10] D. Nusyirwan, "Engineering Design Process Engineering Student Centered Experience Learning (ESCEL) di Jurusan Teknik Elektro Universitas Maritim Raja Ali Haji (UMRAH)". Jurnal Sustainable Vol. 06, No. 01, pp. 24-35, 2017

[11] J.M. C. Bastien, "Usability testing: a review of some methodological and technical aspects of the method", International Journal of Medical Informatics, Vol. 79, Edisi 4, pp e18-e23, 2010

[12] C. von Saucken, F. Lachner, \& U. Lindemann, "Principles for User Experience What We Can Learn from Bad Examples, International Conference on Kansei Engineering \& Emotion Research, 2014

[13] G. I. Johnson, \& C. W. Clegg, \& S. J. Ravden, Towards Practical User Experience Evaluation Methods, Applied Ergonomics, Volume 20, Edisi 4, pp 255-260, Elsevier Ltd, 1989 